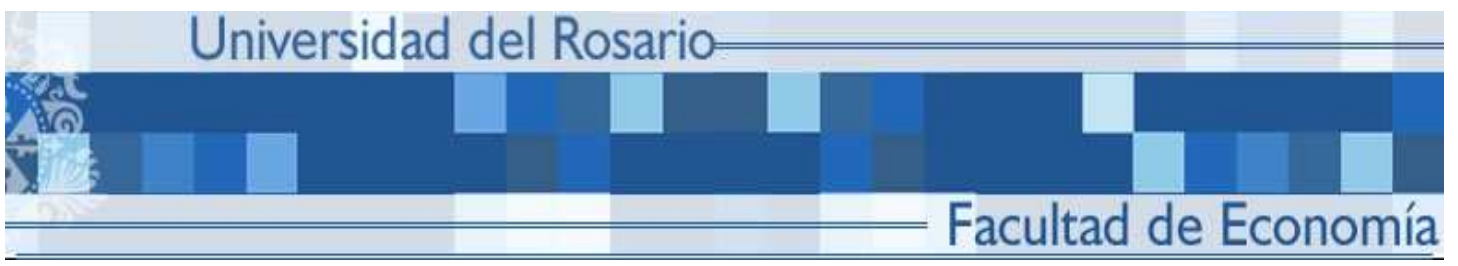

\title{
A model of school behavior: Tuition fees and grading standards
}

Darío Maldonado

(Universidad del Rosario - Deparment of Economics and Ceiba Complejidad)

\section{SERIE DOCUMENTOS DE TRABAJO}

$$
\text { No. } 53
$$




\title{
A model of school behavior: Tuition fees and grading standards
}

\author{
Darío Maldonado *ił
}

October 17, 2008

\begin{abstract}
This paper uses a hybrid human capital / signaling model to study grading standards in schools when tuition fees are allowed. The paper analyzes the grading standard set by a profit maximizing school and compares it with the efficient one. The paper also studies grading standards when tuition fees have limits. When fees are regulated a profit maximizing school will set lower grading standards than when they are not regulated. Credit constraints of families also induce schools to lower their standards. Given that in the model presented competition is not feasible, these results show the importance of regulation of grading standards.
\end{abstract}

\section{Introduction}

In many countries there is an ongoing debate about the need to reform regulatory frameworks for education. The two main issues discussed are financing problems and the need to increase students' achievement levels. The economics literature and policy makers recognize that these two issues are related. The usual argument depends on the effect of the pool of students (through the peer group effect) and of school resources on quality of education. The importance of the peer group effect has led to the idea that

\footnotetext{
${ }^{*}$ Universidad del Rosario (Department of Economics and CeiBA - Complejidad), Bogotá.

†Address: Universidad del Rosario, Facultad de Economía, Calle 14 \# 4-80, Bogotá, Colombia. Phone: (571) 6940579. E-mail: dario.maldonadoca@urosario.edu.co.

${ }^{\ddagger}$ This paper is a modified version of a paper that circulated previously with the title "Grading standards under monopolistic provision of education". I thank comments and suggestions by David Bardey, Helmuth Cremer, Darwin Cortés, Robert Dur, Guido Friebel and Francois Maniquet.
} 
careful consideration of rationing mechanisms that affect the mix of students at school (like tuition fees, scholarships, vouchers or the introduction of charter and magnet schools) may improve quality of education (Nechyba, 2006). The objective of this paper is to analyze another important potential channel that links quality of education and the way school systems are financed (publicly, through the market or through the market with regulatory constraints). This channel emphasizes the relation between willingness to pay for education and the grading standards. This channel brings new policy recommendations and affects the way empirical results about quality of education are interpreted.

The main question addressed in this paper is about the relation between the grading standards used by schools and the way schools are financed. I point to a particular relation between the value individuals give to degrees and their willingness to pay for attending school. Grading standards have a very important role in determining quality of education since they can be used to influence students' achievement (see Betts and Grogger, 2003; Figlio and Lucas, 2004). However, since individuals usually differ in their ability (and consequently in the effort they must make to achieve a particular grading standard), the value attached to the grading standard varies in very important ways with ability. Consequently, the value individuals give to education also varies with ability linking willingness to pay for education and the grading standard and affecting the way schools set their grading standards.

A discussion of these issues must consider the relation between students and schools or teachers, and also the characteristics of the labor market. On the one hand, students and schools are the main players in the education market; tuition fees and grading standards may have important incentive effects on both types of players which makes it important to have a model where both are present. On the other hand, if one wants to have a meaningful role for degrees one should consider a model where degrees have real and important consequences for students. For this reason I use the human capital / signaling hybrid model introduced by Betts (1998). ${ }^{1}$ This implies that the best model to think about education is one that accounts for both phenomena. Individual productivity depends on individual ability and effort at school but firms do not observe individual productivity which makes

1. The evidence on whether the effects of investment in education in the labor market are best described by a human capital or a signaling model is mixed (see Kroch and Sjoblom, 1994; Lang and Kropp, 1986; Riley, 1979; Wolpin, 1977). This justifies the use of a model that accounts for both phenomena. 
degrees important signaling devices. Individuals maximize utility and effort is costly for them. Schools maximize profits and education is a costly task. ${ }^{2}$

There is a wide existing literature concerned with education, however there is not much on the issue of how grading standards are chosen by teachers or school mangers. The main related papers are De Fraja and Landeras (2006) and Brunello and Rocco (2008). ${ }^{3}$ De Fraja and Landeras (2006) use a different model where grading results from an ad-hoc function and not from assumptions about the value of degrees to students and they concentrate on numerical results. Brunello and Rocco (2008) is much more related to the present paper; they use a very similar model and also ask for similar questions. However, they loose generality assuming specific functional forms instead of general functions which does not allow them to analyze the forces involved in the grading standard / tuition decision. More important, I also address how restrictions on tuition fees chosen by schools affect grading standards which is important given that in most countries these restrictions are present. Other related contributions are Betts (1998) and Costrell (1994) who dwell with the determinants of efficient grading standards and of the grading standards that result when set by majority voting. They do not consider the relation between grading standards and tuition fees and do not address the problem of how grading standards are

2. Whether schools are accurately described as profit maximizing institutions is an unresolved issue. Clearly the distinction between non-profit and for-profit based on whether there is a third party (shareholders) that claims economic benefits is not enough. Educational institutions can be managed by administrators or teachers that want resources for activities in their interests ( $v . g$. low teaching or administrative loads, nice buildings or research in the case of universities.). My choice of objective function answers to the fact that whatever the objective schools have, if schools face resource constraints they may want to maximize profits obtained from tuition fees. Probably my specification will not accurately match reality in quantitative terms, but still it shows important mechanisms that emerge when schools are subject to budget pressures. Epple and Romano (1998) and Epple, Romano and Siege (2003) are two good examples of this point; the models used in both papers are very similar, the main difference is that in the first schools are profit maximizers and in the second they maximize quality. Still, they both yield very similar qualitative conclusions about the behavior of schools and the market outcome.

3. Although not directly concerned with education, Lizzeri (1999) is also related. He analyzes a different setting, namely that of certification agencies. He studies the optimal strategy of a certification agency that has some information about the quality of a good and can choose whether to disclose it to a potential buyer. The main difference between my paper and Lizzeri's is that he considers a pure adverse selection model while the problem of education posed in my paper requires a model with adverse selection and moral hazard. 
chosen by schools. ${ }^{4}$

The baseline argument in this paper is that the choice of grading standard by a profit concerned school is affected in very important ways by the rules affecting tuition fees. The efficient grading standard is such that the marginal student (the lowest ability student achieving the degree) would benefit from a reduction in the standard. In the efficient allocation, the government trades off the sum of effort disutility of all students and benefits in terms of increasing overall labor market productivity. Being unable to tailor the standard to the ability of students individually, the government must set a grading standard such that low-ability (high-ability) students achieving the degree would benefit from a reduction (increase) of the standard. However, the profit maximizing school will tailor the grading standard to maximize the willingness to pay of the marginal student so as to maximize the tuition fee that can be extracted from students.

If the school chooses the tuition fee together with the grading standard, for a given marginal student, the efficient standard would be higher than the one set by the profit maximizing school; a grading standard which is lower than the efficient one allows the school to charge higher tuition fees. If the school is not free to choose the tuition fee charged to students and faces a cap (because of regulation or because of families' credit constraints) the school would reduce the grading standard since that will allow them to increase profits through a higher demand for school enrollment. When the school receives a payment per student from the government, willingness to pay for tuition is disconnected from its quality; if a lower standard is related to higher demand ${ }^{5}$ the grading standard will be inefficiently low.

An additional and important result is related to the comparison of the efficient grading standard with that set by the profit maximizer school when there is a cap on tuition fee. I show in this paper that the efficient grading standard increases with the cap on the fee while the decentralized standard decreases with the cap. Since in most countries tuition fees are regulated (if allowed at all), this result shows the importance of regulating grading standards and that this importance grows when limits on tuition fees are lower. These results shed light on the optimal instruments that must be used to regulate schools. The main lesson is that regulating tuition fees will lower grading standards. To avoid this effect, regulation of schools must also

4. Also related is Gary-Bobo and Tranoy (2005) but the paper concentrates on admission standards instead of graduation standards.

5. I will show conditions such that this holds 
include instruments to directly or indirectly control the grading standard used by the school. Instruments like the baccalaureat in France or national state exams in many other countries can be very useful to incentivize schools by linking students' results to the economic received by schools or teachers.

The paper proceeds as follows. Section 2 presents the assumptions of the model, describes individuals' behavior and the labor market outcome. Section 3 analyzes the (second-best) efficient outcome. The main results of the paper are analyzed in Section 4 where the problem of the profit maximizing school is solved and compared with the efficient outcome. The last section concludes.

\section{The model}

This section describes the main assumptions of the model, the behavior of individuals and the labor market equilibrium.

\subsection{Assumptions}

Assume a continuum of individuals indexed by $i$. Each individual has a utility function

$$
u^{i}=w^{i}-t-v\left(e^{i}\right)
$$

and a labor market productivity $\omega\left(\phi^{i}, e^{i}\right)$. Wages are represented by $w^{i}$, $t$ represents the payment for tuition by students, $e^{i}$ her effort at school and $\phi^{i}$ her ability. $v$ and $\omega$ are strictly increasing in all arguments. $\omega$ is concave in both arguments and satisfies $\omega_{\phi e} \geq 0 . v$ is convex. Ability is exogenously given, it is distributed with a cumulative distribution function $F$ with support $\left[\phi^{L}, \phi^{H}\right]{ }^{6}$

For simplicity I assume that there is only one school whose only task is to provide degrees. This assumption allows the study of the effect of profit maximization on grading standards; settings in which there are more schools are left for future research. The objective function of the school is given by

$$
\Pi=\pi[t-\gamma]
$$

6. The dependence of labor market productivity on ability has been widely recognized by the empirical literature; evidence for the dependence on effort at school is more scarce, recently Stinebrickner and Stinebrickner (2008) show evidence that support this assumption. 
where $\pi$ is the number of students who attend the school and $\gamma$ the marginal cost of serving one student. The school has a technology (an exam) that allows it to determine whether the productivity of a student is above or below a certain threshold $\underline{\omega}$. The school will award a degree to a student if her productivity is above that threshold. Let

$$
D^{i}= \begin{cases}d & \text { if } \omega\left(\phi^{i}, e^{i}\right) \geq \underline{\omega} \\ f & \text { otherwise }\end{cases}
$$

represent whether the student $i$ achieves the degree or not.

The labor market is imperfect. Firms do not observe individual productivity, they only observe whether the individual achieved a degree or not. Consequently wages can only be conditioned on $D^{i}$. The wage of an individual $i$ is given by

$$
w^{i}=E\left[\omega\left(\phi^{i}, e^{i}\right) \mid D^{i}\right] .
$$

As will be clear later no individual would attend school and not achieve the degree. Consequently, there will be only two wage levels observed in the labor market one for individuals that achieved the degree, $w^{d}$, and one for those that did not attend school, $w^{u}$.

The timing of the game is as follows. In the first stage the school chooses $\underline{\omega}$ and $t$. In the second stage individuals decide whether to attend school and the effort they will make. In the third stage individuals go to the labor market and earn wages according to equation (1).

\subsection{The behavior of individuals}

The behavior of individuals is characterized by two properties. The first says that individuals make the minimum effort needed. The second shows the monotonicity property for the decision of whether to achieve a degree or not. The appendix provides proofs for both properties.

Minimal effort. Let $\varepsilon^{i}=\max \left\{\underline{e}^{i}, 0\right\}$ where $\omega\left(\phi^{i}, \underline{e}^{i}\right)=\underline{\omega}$. The optimal effort of a type- $i$ student is $\varepsilon^{i}$.

This property says that the optimal effort of an individual who finds it suboptimal to achieve the degree is equal to zero. Among individuals who decide to attend school, effort will decrease with ability and will equal zero for those with very high ability. Those students who exert an effort level greater than zero will end up with a productivity equal to the grading 
standard; the productivity of those who do not exert effort but achieve the degree will be greater than the grading standard. ${ }^{7}$ Note that $\varepsilon^{i}$ is a function of $\phi^{i}$ and $\underline{\omega}$; to spare notation I will omit the arguments of $\varepsilon^{i}$ in this paper.

Monotonicity. If a student with ability $\phi^{i}$ chooses (not) to achieve the degree, all students with ability $\phi^{h} \geq(\leq) \phi^{i}$ will (not) choose to achieve the degree.

From the monotonicity property and the continuity of the support of $\phi^{i}$, there is a marginal student who is indifferent between achieving the degree and not achieving it. Let the ability of this student be represented by $\widetilde{\phi}$.

\subsection{Wages and comparative statics}

In section $2.1 \mathrm{I}$ argued that only two wages are observed in the labor market. Using the two properties discussed in the previous subsection wages can be written as follows:

$$
\begin{aligned}
w^{d}(\widetilde{\phi}, \underline{\omega}) & =E\left[\omega\left(\phi^{i}, \varepsilon^{i}\right) \mid \phi^{i} \geq \widetilde{\phi}\right]=\underline{\omega} \frac{F(\Phi)-F(\widetilde{\phi})}{1-F(\widetilde{\phi})}+\int_{\Phi}^{\phi^{H}} \omega\left(\phi^{i}, 0\right) \frac{d F\left(\phi^{i}\right)}{1-F(\widetilde{\phi})} \\
w^{u}(\widetilde{\phi}) & =E\left[\omega\left(\phi^{i}, 0\right) \mid \phi^{i}<\widetilde{\phi}\right]=\int_{\phi^{L}}^{\widetilde{\phi}} \omega\left(\phi^{i}, 0\right) \frac{d F\left(\phi^{i}\right)}{F(\widetilde{\phi})}
\end{aligned}
$$

where $\Phi$ represents the ability level at which there is no need to exert effort to achieve the grading standard $(\omega(\Phi, 0)=\underline{\omega})$.

Define

$$
\Delta\left(\phi^{i}, \underline{\omega}\right) \equiv\left[w^{d}\left(\phi^{i}, \underline{\omega}\right)-v\left(\varepsilon^{i}\right)\right]-w^{u}\left(\phi^{i}\right)
$$

as the willingness to pay for attending school and achieving the degree for an individual of ability $\phi^{i}$ if she is the marginal individual. Then, in equilibrium, $\widetilde{\phi}$ must satisfy

$$
\Delta(\widetilde{\phi}, \underline{\omega})-t=0 .
$$

Equation (3) defines implicitly the ability of the marginal individual as a function of $\underline{\omega}$ and $t$. Let this function be $\widetilde{\phi}(\underline{\omega}, t)$. The comparative statics of $\widetilde{\phi}$ are given by

$$
\widetilde{\phi}_{t}(\underline{\omega}, t)=\frac{1}{\Delta_{\phi}(\widetilde{\phi}, \underline{\omega})}, \quad \widetilde{\phi}_{\underline{\omega}}(\underline{\omega}, t)=-\frac{\Delta_{\underline{\omega}}(\tilde{\phi}, \underline{\omega})}{\Delta_{\phi}(\widetilde{\phi}, \underline{\omega})}
$$

7. Given that we have a continuum of abilities, there is a mass zero of individuals that exert zero effort and have a productivity equal to the grading standard 
which follow from the differentiation of (3). In the previous expressions and in the rest of the paper, subscripts on functions denote partial derivatives.

From inspection of the expressions for $\Delta_{\underline{\omega}}$ and $\Delta_{\phi}$, provided in the appendix we can show that if $\Delta_{\phi}(\widetilde{\phi}, \underline{\omega})>0$, then

$$
\begin{aligned}
\widetilde{\phi}_{t}(\underline{\omega}, t) & >0, \\
\operatorname{sign}\left(\widetilde{\phi}_{\underline{\omega}}(\underline{\omega}, t)\right) & =-\operatorname{sign}\left(\Delta_{\underline{\omega}}(\widetilde{\phi}, \underline{\omega})\right) .
\end{aligned}
$$

The condition that $\Delta_{\phi}>0$ is intuitive: the better the pool of students achieving the degree, the larger their surplus. Moreover it has intuitive implications. The first implication is that increasing the tuition will reduce demand for school; this implication needs little explanation.

The second implication is that increasing the grading standard will increase the ability of the marginal student if it also reduces the value of achieving the degree (for a given marginal individual). To understand this comparative static, it is very important to note that increasing the standard has the benefit of increasing the differential between $w^{d}$ and $w^{u}$ but it also increases the effort cost of achieving the degree. The sign of $\Delta_{\underline{\omega}}$ depends on the value of the grading standard itself and can be positive or negative. To see this write

$$
\Delta_{\underline{\omega}}(\widetilde{\phi}, \underline{\omega})=\frac{F(\Phi)-F(\widetilde{\phi})}{1-F(\widetilde{\phi})}-\frac{v^{\prime}(\widetilde{\varepsilon})}{\omega_{e}(\widetilde{\phi}, \widetilde{\varepsilon})}
$$

which is the marginal utility of $\underline{\omega}$ for the marginal individual. Note that the first term on the right hand side is less than one but the second term can be larger or smaller than one depending on the value of $\widetilde{\varepsilon}$. In particular, if the standard induces an $\widetilde{\varepsilon}$ which is greater than the optimal effort level under perfect information conditions ${ }^{8}$ then $\Delta_{\underline{\omega}}(\widetilde{\phi}, \underline{\omega})<0$. For lesser effort levels, there is a region for which $\Delta_{\underline{\omega}}(\widetilde{\phi}, \underline{\omega})<0$ (for $\underline{\omega}$ inducing high effort values for which $v^{\prime}\left(\varepsilon^{i}\right) / \omega_{e}\left(\phi^{i}, \varepsilon^{i}\right)$ is still lower than 1$)$ and a region for which $\Delta_{\underline{\omega}}(\tilde{\phi}, \underline{\omega})>0$ (for $\underline{\omega}$ inducing lower effort values).

Even if it is intuitive to think that $\Delta_{\phi}(\widetilde{\phi}, \underline{\omega})>0$ the sign of $\Delta_{\phi}(\widetilde{\phi}, \underline{\omega})$ still remains ambiguous. ${ }^{9}$ For the time being I will suppose that this is true; further in this paper I will show that, with a profit maximizing school, in equilibrium only this can be the case. ${ }^{10}$

8. This is the effort that solves $\omega_{e}(\widetilde{\phi}, e)=v^{\prime}(e)$.

9. Assuming $t=0$ Betts (1998) shows that $\Delta_{\phi}(\tilde{\phi}, \underline{\omega})>0$ holds in stable equilibria. The result holds also for different values of $t$ if it is exogenous.

10. See equation (12) and the corresponding explanation in page 4.1. 


\section{The efficient tuition fee and grading standard}

I turn now to the analysis of the efficient outcome of this model. I will analyze the case where the planner maximizes the sum of individual utilities constrained by the same restrictions on information faced by the school: it can only observe whether individual productivity is above or below $\underline{\omega}$. The problem solved in this section is very similar to that solved by Betts (1998) with the difference that I introduce tuition fees. The introduction of the tuition fee allows to show its interplay with the grading standard.

The government plays in the first stage of the game anticipating individuals' behavior. The problem of the government is given by

$$
\max _{\underline{\omega}, t} \quad[1-F(\widetilde{\phi})] w^{d}(\widetilde{\phi}, \underline{\omega})+F(\widetilde{\phi}) w^{u}(\widetilde{\phi})-\int_{\widetilde{\phi}}^{\Phi} v\left(\varepsilon^{i}\right) d F\left(\phi^{i}\right)-[1-F(\widetilde{\phi})] \gamma
$$

where, to spare notation, I have drop the arguments of $\widetilde{\phi}(\underline{\omega}, t)$. Note that as a consequence of the utilitarianism and quasiconcavity of utility assumptions, the government is indifferent about the distribution of utility between individuals and the distribution of surplus between individuals and the school. This means that the government does not directly care about tuition fees, except as an instrument to control $\widetilde{\phi}$.

After some manipulations (using 3 ) the first-order conditions of the welfare maximization problem (provided in the appendix) yield

$$
\begin{gathered}
t^{*}=\underbrace{\gamma}_{1}+\underbrace{\left[w^{d}-w^{u}\right]}_{2}-\underbrace{\left[\underline{\omega}^{*}-\omega\left(\widetilde{\phi}\left(\underline{\omega}^{*}, t^{*}\right), 0\right)\right]}_{3}, \\
F(\Phi)-F\left(\widetilde{\phi}\left(\underline{\omega}^{*}, t^{*}\right)\right)=\int_{\widetilde{\phi}\left(\underline{\omega}^{*}, t^{*}\right)}^{\Phi} \frac{v^{\prime}\left(\varepsilon^{i}\right)}{\omega_{e}\left(\phi^{i}, \varepsilon^{i}\right)} d F\left(\phi^{i}\right)
\end{gathered}
$$

where $\underline{\omega}^{*}$ and $t^{*}$ represent the efficient grading standard and tuition fee.

Equations (6) and (7) describe the welfare maximizing tuition fee and grading standard. These equations show that in the optimum there is a separation between the two objectives of the government, namely sorting (which individuals should achieve the degree) and inducing optimal effort levels. The tuition fee is used to achieve the optimal number of individuals achieving the degree, the grading standard is used to give students incentives for effort. The optimal tuition fee is greater than the marginal $\operatorname{cost}^{11}$ and

11. This follows from $\underline{\omega}<w^{d}$ and $\omega(\widetilde{\phi}, 0)>w^{u}$. 
is composed of three terms. The first term is the marginal cost, the second term equals the individual gain from attending school and the third term the social gain of letting an individual with ability $\widetilde{\phi}$ attend school. The second and third terms explain why the optimal tuition fee must be higher than the marginal cost. The second term is a Pigouvian term: the optimal tuition fee extracts the externality an individual receives from achieving the degree. This externality results from the information problems in the labor market. However, the government cannot completely extract this externality without hampering the benefits to exert effort, the third term rewards effort.

The main feature of the equation governing the grading standard is that it is set to equate its marginal cost and benefit. The marginal benefit of increasing the standard is given by the mass of students who would increase their effort and would have a higher productivity. The marginal cost is equal to the sum of the marginal disutilities of effort of all students.

Suppose now that there is some external limit on the tuition fee. This limit can be given by credit constraints faced by individuals or by political constraints that limit the power of the government to charge tuition fees. Letting $\tau$ denote the upper bound on the tuition fee and $\underline{\omega}^{\tau}$ denote the resulting optimal grading standard, the first order condition for the grading standard (when $t^{*}>\tau$ ) takes the form:

$$
\begin{aligned}
F(\Phi)-F\left(\widetilde{\phi}^{\tau}\right) & =\int_{\widetilde{\phi}^{\tau}}^{\Phi} \frac{v^{\prime}\left(\varepsilon^{i}\right)}{\omega_{e}\left(\phi^{i}, \varepsilon^{i}\right)} d F\left(\phi^{i}\right) \\
& -\left\{\left[w^{d}-w^{u}\right]-\left[\underline{\omega}^{\tau}-\omega\left(\widetilde{\phi}^{\tau}, 0\right)\right]-(\tau-\gamma)\right\} f\left(\widetilde{\phi}^{\tau}\right) \widetilde{\phi}_{\underline{\omega}}^{\tau}
\end{aligned}
$$

where, to simplify notation, I have replaced $\widetilde{\phi}\left(\underline{\omega}^{\tau}, \tau\right)$ by $\widetilde{\phi}^{\tau}$. In this expression a new term appears and has the same interpretation as the terms appearing in the optimal efficient fee. If there are restrictions that limit the power of the fee to solve the sorting issue it is optimal to amend the grading standard for this purpose. As before we have a Pigouvian and an incentives term. Since the second term in the right hand side of (8) is negative, by concavity, the grading standard will be higher when there are limits on the tuition fee than in the absence of these limits. If the grading standard is not amended for this purpose there would be too many low ability students achieving the degree; the grading standard is increased to avoid this to happen.

Expression (8) is similar to that determining the efficient grading standard in Betts (1998), but it is slightly more general since it accounts for 
tuition fees that are different from zero. To get the expression that determines the grading standard when tuition fees are simply not possible it is enough to set $\tau=0$.

An important implication of equations (7) and (8) that will be used further in this paper is that in both cases considered in this section, the effort of the marginal individual satisfies ${ }^{12}$

$$
\frac{F(\Phi)-F(\widetilde{\phi})}{1-F(\widetilde{\phi})}<\frac{v^{\prime}(\widetilde{\varepsilon})}{\omega_{e}(\widetilde{\phi}, \widetilde{\varepsilon})}
$$

From the expression for $\Delta_{\underline{\omega}}$ (see section A.3 in the appendix) it follows that $\Delta_{\underline{\omega}}<0$, or that the marginal student would benefit from a reduction in the grading standard (her utility would be higher if the standard is marginally reduced). This also implies that in the efficient solution $\widetilde{\phi}_{\underline{\omega}}>0$.

The intuition for this result is as follows. Information asymmetries place the efficient policies in a second-best situation. In this second best situation the efficient grading standard will be tailored to average utility. Setting a grading standard which is optimal from the point of view of the marginal individual would have the cost of inducing too little effort by individuals with abilities $\phi^{i} \geq \tilde{\phi}$. Inducing greater effort by those individuals implies setting a grading standard that requires an effort by the marginal individual which is above her optimal effort.

\section{Optimal tuition fee and grading standard for a profit maximizing school}

In this section I consider two situations. First, the problem of a monopolist school that decides upon $t$ and $\underline{\omega}$. Then I consider the situation when the monopolist is not able to charge a tuition fee but receives a payment per student from the government. The main objective is to compare the grading standard set by the profit maximizing school with the efficient grading standard.

12. Equation (9) follows from noticing that

$$
\int_{\widetilde{\phi}(\underline{\omega}, t)}^{\Phi} \frac{v^{\prime}\left(\varepsilon^{i}\right)}{\omega_{e}\left(\phi^{i}, \varepsilon^{i}\right)} d F\left(\phi^{i}\right)<\int_{\widetilde{\phi}(\underline{\omega}, t)}^{\phi^{H}} \frac{v^{\prime}(\widetilde{\varepsilon})}{\omega_{e}(\widetilde{\phi}, \widetilde{\varepsilon})} d F\left(\phi^{i}\right)=(1-F(\widetilde{\phi})) \frac{v^{\prime}(\widetilde{\varepsilon})}{\omega_{e}(\widetilde{\phi}, \widetilde{\varepsilon})} .
$$

Where the first inequality follows from the facts that $\varepsilon^{i}$ is decreasing in $\phi^{i}$ and $v^{\prime}\left(\varepsilon^{i}\right) / \omega_{e}\left(\phi^{i}, \varepsilon^{i}\right)$ is increasing in $\varepsilon^{i}$. 


\subsection{First order conditions}

From the monotonicity property of individual behavior we can write the school's objective function as $[1-F(\widetilde{\phi})][t-\gamma]$. The problem of the school is to maximize profits subject to optimality of individuals' choices in subsequent periods; this means that $\widetilde{\phi}$ satisfies (3). The problem of the school is thus

$$
\max _{\underline{\omega}, t} \quad[1-F(\widetilde{\phi}(\underline{\omega}, t))][t-\gamma] .
$$

Letting $\underline{\omega}^{\pi}$ and $t^{\pi}$ represent the grading standard and tuition that solve this problem, the first-order conditions for an interior optimum of this problem are

$$
\begin{aligned}
-f\left(\widetilde{\phi}\left(\underline{\omega}^{\pi}, t^{\pi}\right)\right) \widetilde{\phi}_{t}\left(\underline{\omega}^{\pi}, t^{\pi}\right)\left[t^{\pi}-\gamma\right]+\left[1-F\left(\widetilde{\phi}\left(\underline{\omega}^{\pi}, t^{\pi}\right)\right)\right]=0, \\
-f\left(\widetilde{\phi}\left(\underline{\omega}^{\pi}, t^{\pi}\right)\right) \widetilde{\phi}_{\underline{\omega}^{\pi}}\left(\underline{\omega}^{\pi}, t^{\pi}\right)\left[t^{\pi}-\gamma\right]=0 .
\end{aligned}
$$

The optimal tuition fee follows from the two previous equations. Rearranging (10) it follows that

$$
t^{\pi}=\gamma+\frac{1-F\left(\widetilde{\phi}\left(\underline{\omega}^{\pi}, t^{\pi}\right)\right)}{f\left(\widetilde{\phi}\left(\underline{\omega}^{\pi}, t^{\pi}\right)\right) \widetilde{\phi}_{t}\left(\underline{\omega}^{\pi}, t^{\pi}\right)} .
$$

This expression proves that with a profit maximizing school and no government intervention only equilibria where $\hat{\phi}_{t}>0$ (and thus where $\Delta_{\phi}>0$ ) will emerge in this model. Equilibria where $\hat{\phi}_{t}<0$ result in $t<\gamma$ and the school would make negative profits so no profit maximizing school would operate.

From the first order condition for $\underline{\omega}$ :

$$
\widetilde{\phi}_{\underline{\omega}}\left(\underline{\omega}^{\pi}, t^{\pi}\right)=0
$$

which implies

$$
\Delta_{\underline{\omega}}\left(\widetilde{\phi}\left(\underline{\omega}^{\pi}, t^{\pi}\right), \underline{\omega}^{\pi}, t^{\pi}\right)=\frac{F(\Phi)-F\left(\widetilde{\phi}\left(\underline{\omega}^{\pi}, t^{\pi}\right)\right)}{1-F\left(\widetilde{\phi}\left(\underline{\omega}^{\pi}, t^{\pi}\right)\right)}-\frac{v^{\prime}(\widetilde{\varepsilon})}{\omega_{e}\left(\widetilde{\phi}\left(\underline{\omega}^{\pi}, t^{\pi}\right), \widetilde{\varepsilon}\right)}=0 .
$$

This equation says that the profit maximizing school sets the standard in order to induce the marginal student to exert the effort that is optimal from her point of view. This results from the fact that the school assigns no intrinsic value to the grading standard; it only values the grading standard if it directly affects willingness to pay for attending school. Consequently, it sets the grading standard to maximize the willingness to pay for tuition by the marginal student. 


\subsection{Implications}

Comparison of (7) and (13) shows the inefficiency of the grading standard set by the profit concerned school. The source of the inefficiency is that the profit maximizing school cares only for the welfare of the marginal individual, while in the efficient solution, effort disutility of all students is taken into account.

In general it is not possible to unambiguously compare the tuition fees and gradings standards of both outcomes. However, some interesting partial comparisons can be made. First consider the grading standard conditional on a given tuition fee. Equation (9) shows that, in the efficient solution, the marginal student would receive higher utility if the standard was reduced. This means that, fixing the tuition fee to the efficient value, the profit maximizing school could make a marginal reduction in the standard increasing demand and profits. This means that given a tuition fee equal to the efficient one, the profit maximizing school would set an inefficiently low grading standard.

Second, consider a situation where the marginal student is fixed at the efficient level, i.e. $\widetilde{\phi}$ is given by equation (7). In this case, the for-profit school sets a higher tuition fee than the welfare maximizing solution and a lower grading standard. This follows from equation (9), which says that the efficient marginal student would want a lower standard; if the standard is reduced she would be willing to pay a higher fee for attending school. The school would get higher profits in this new situation. A consequence of this is that the effort induced by a profit maximizing school will be lower than the efficient one.

To summarize, marginally, the profit maximizing school sets a lower grading standard and a higher tuition fee than the those which are efficient. These comparisons are very useful to think about how schools that face budgetary pressures will respond to policies but do not allow us to say whether the observed tuition fee and grading standard of the profit maximizing school are higher or lower than the efficient ones.

Given the institutional settings in which schools normally operate it makes sense to consider the effect of tuition fees limits. There are several cases that can be considered and are the same already considered in Section 3. First, the absolute absence of tuition fees together with external financing of schools. Second, one can also consider limits on tuition fees that are due either to regulatory constraints or to credit constraints faced by families. 
Consider the case in which the school is not allowed to charge tuition fees and receives the resources to finance its operation from external sources (typically from the government). Suppose that the school receives a per student payment $\bar{t} \geq \gamma$. Under these conditions the school will set a grading standard that induces all students to attend the school and achieve the degree. This follows from equations (4) and (5) and Lemma 1 in the appendix, which show that when students do not make payments to school it will always be that $\widetilde{\phi}_{\underline{\omega}}>0$; this means that a reduction in the standard will always reduce the ability of the marginal student. Since $\bar{t}$ is fixed, the school will always want to reduce the standard to increase demand since that will always increase profits. If students do not have to pay to attend school, the only reason not to attend would be if the standard is to high; however, the school would not want to set a high standard since there is no relation between the level of the standard and the tuition fee students are willing to pay.

Now suppose that tuition fees are allowed but there is a cap on them. Assume also that the school is inducing some students to stay out of school. The important question now is whether the grading standard is higher or lower than $\underline{\omega}^{\pi}$. To find the answer consider what happens if the school sets the standard at the level which maximizes profits if there were no constraints on the fee (i.e. it lets $\underline{\omega}^{\pi}$ be the standard) and lets the fee equal the maximum allowed value. At this point, the individual who was marginal in the unrestricted solution has strictly positive surplus from attending school. By continuity, there are some students with lower ability willing to attend school. The new marginal student will be one with lower ability. But $\underline{\omega}^{\pi}$ cannot maximizes profits. If the grading standard that maximizes the willingness to pay for attending school is decreasing in ability ${ }^{13}$ the grading standard will be lower than in the absence of constraints on $t$ since that will raise demand further. Thus, it turns out that the grading standard would be lower than the one that results when there are no limits on the fee. Moreover, the same type of argument shows that the lower the limit the lower the standard.

Two important implications follow from the previous analysis. First, note the differences in how the efficient and the profit maximizing grading standard reacts to tuition fee limits. While the first increases with the cap on tuition the second decreases. Thus the lower the cap the more important

13. In the section A.6 of the appendix I show that the most preferred grading standard of an individual is increasing in her ability if $\omega$ is concave in $\phi, \omega_{\phi e} \geq 0$ and the hazard rate is increasing. 
it is to introduce instruments to regulate grading standards. Second, we have the question of the effect of a regulation that forces schools to set a tuition fee that equals the efficient one, in this case the school would set an inefficiently low grading standard.

A similar argument can be made to show that if there are credit constraints and student's capacity to pay is limited by family resources, the grading standard will be lower than in the absence of credit constraints. This means that one can expect policies that relax credit constraints to have the effect of increasing grading standards.

\section{Concluding comments}

In this paper I have addressed the relation between financing of school attendance and the grading standards used by institutions that face budget pressures. The model I used takes into account students' ability and effort as the crucial determinants of school achievement. To have a meaningful role for grading standards I assumed imperfections in the labor market that set limits on wages.

The main contribution of the paper is that it identifies the sources of inefficiencies implied by budget pressures in the grading standards set by school managers or by teachers. Under information asymmetries in the labor market, the wage of individuals that achieved the degree is equal to average marginal productivity of all individuals who achieved the degree. This implies that the efficient grading standard is set according to average utility. Individuals, however, due to differences in the costs they must assume to achieve the degree, have different willingness to pay for attending school. Profit maximizing schools do not care about all the students that attend school, they only care about the marginal student since the maximum tuition that can be extracted depends on her willingness to pay for education. For-profit schools are concerned only with the utility of the marginal individual and this causes inefficient grading standards.

Ideally the results of this paper should be used to understand the available empirical results on grading standards used by schools. Probably the most urgent task is understanding the results regarding the difference in achievement in private and public schools. If one believes that the outcome of having a public school is correctly described by that from section 3 where the efficient grading standard was studies the comparison with the private 
school is ambiguous. However one can also think that the main difference between public and private schools is the ability of the former to charge tuition fees while the second will be financed with public resources. In such a case my model predicts that public schools will set lower standards than private schools. ${ }^{14}$ The model then predicts that students of public schools have lower results in achievement tests than students of private schools. However, as argued by Hanushek (2002) the empirical literature is not conclusive about the difference in achievement between students from private and public schools. One of the main difficulties in the literature is that it has not linked the institutional features of education markets and the regulatory constraints to the problem. The results in this paper do suggest avenues of research for the empirical literature, particularly, considering the link between grading standards and tuition limits (due to regulation or credit constraints) may help finding conclusive answers to the problem.

The main message of the paper is that the design of education finance schemes must take into account interactions with the grading standards used by schools. If school managers or teachers are not concerned with grading standards per se, or if budget pressures are strong relative to other possible objectives of the school, restricting the power of schools to charge tuition fees may result in inefficiently low grading standards. Policies that introduce school finance schemes other than tuition fees should also consider the impact they may have on grading standards used by schools.

In this paper I have assumed a single school which may be an accurate description of reality in many cases due to transportation costs or spacial issues related to education demand. However, the effect of competition cannot be neglected. It must, however, be clear that the main mechanism present in the paper is independent of the monopoly assumption. Perfect competition is not an alternative in a setting like the one in this paper; once there is some degree of monopolistic power the problem of budget pressures causing schools to over look the willingness to pay of the marginal student would generate the same type of inefficiencies as in the cases considered in this paper. ${ }^{15}$ Competition may have important implications on the education market outcome in more complicated cases in which heterogeneity in other

14. Brunello and Rocco (2008) take a different approach and suppose that grading standards in public schools are chosen by majority voting. They show that standards of public schools may be higher than those of private schools. This already supposes that grading standards are not disconnected from tuition fees and is in the way of supposing a regulated school.

15. A similar point is made by Spence (1975) in a different setting. 
dimensions (like wealth) are considered or under less restrictive specifications of preferences of schools. 


\section{A Appendix}

\section{A.1 Proof of the Minimal effort property}

Suppose an individual wants to achieve the degree and decides to exert an effort level $e^{i}>\varepsilon^{i}$; let $u^{i}$ and $u^{\varepsilon i}$ be, respectively, the utility levels from exerting $e^{i}$ and $\varepsilon^{i}$. This would mean that $u^{i}>u^{\varepsilon i}$. Since wage cannot be conditioned on effort this implies $v\left(e^{i}\right)<v\left(\varepsilon^{i}\right)$ which is clearly a contradiction. An individual that decides not to achieve the degree faces a similar problem that leads to zero effort.

\section{A.2 Proof of the Monotonicity property}

Consider two individuals with ability levels $\phi^{\prime}$ and $\phi^{\prime \prime}$ and let their minimal efforts needed to achieve the degree be $\varepsilon^{\prime}$ and $\varepsilon^{\prime \prime}$, respectively. Suppose that the individual with ability $\phi^{\prime}$ wants to achieve the degree, then $w^{d}-$ $t-v\left(\varepsilon^{\prime}\right) \geq w^{u}$. If $\phi^{\prime \prime} \geq \phi^{\prime}, w^{d}-t-v\left(\varepsilon^{\prime \prime}\right) \geq w^{u}$ since $v\left(\varepsilon^{\prime}\right) \geq v\left(\varepsilon^{\prime \prime}\right)$. Similarly if the individual with ability $\phi^{\prime}$ does not want to achieve the degree, $w^{d}-t-v\left(\varepsilon^{\prime}\right) \leq w^{u}$ and if $\phi^{\prime \prime} \leq \phi^{\prime}, w^{d}-t-v\left(\varepsilon^{\prime \prime}\right) \leq w^{u}$.

\section{A.3 The comparative statics of $\Delta$}

Differentiating (2)

$$
\begin{aligned}
\Delta_{\phi}(\widetilde{\phi}, \underline{\omega}) & =\frac{\partial}{\partial \widetilde{\phi}}\left[w^{d}(\widetilde{\phi}, \underline{\omega})-w^{u}(\underline{\omega})\right]+v^{\prime}(\widetilde{\varepsilon}) \frac{\omega_{\phi}(\widetilde{\phi}, \widetilde{\varepsilon})}{\omega_{e}(\widetilde{\phi}, \widetilde{\varepsilon})} \\
& =\frac{f(\widetilde{\phi})}{1-F(\widetilde{\phi})}\left[w^{d}-\underline{\omega}\right]-\frac{f(\widetilde{\phi})}{F(\widetilde{\phi})}\left[\omega(\widetilde{\phi}, 0)-w^{u}\right]+v^{\prime}(\widetilde{\varepsilon}) \frac{\omega_{\phi}(\widetilde{\phi}, \widetilde{\varepsilon})}{\omega_{e}(\widetilde{\phi}, \widetilde{\varepsilon})}, \\
\Delta_{\underline{\omega}}(\widetilde{\phi}, \underline{\omega}) & =\frac{\partial}{\partial \underline{\omega}}\left(w^{d}-w^{u}\right)-\frac{v^{\prime}(\widetilde{\varepsilon})}{\omega_{e}(\widetilde{\phi}, \widetilde{\varepsilon})} \\
& =\frac{F(\Phi)-F(\widetilde{\phi})}{1-F(\widetilde{\phi})}-\frac{v^{\prime}(\widetilde{\varepsilon})}{\omega_{e}(\widetilde{\phi}, \widetilde{\varepsilon})} .
\end{aligned}
$$




\section{A.4 FOC of the welfare maximization problem}

Welfare can be rewritten as

$$
\begin{aligned}
W=\int_{\Phi}^{\phi^{H}} \omega\left(\phi^{i}, 0\right) d F\left(\phi^{i}\right) & +\underline{\omega}[F(\Phi)-F(\widetilde{\phi})] \\
& +\int_{\phi^{L}}^{\widetilde{\phi}} \omega\left(\phi^{i}, 0\right) d F\left(\phi^{i}\right)-\int_{\widetilde{\phi}}^{\Phi} v\left(\varepsilon^{i}\right) d F\left(\phi^{i}\right)-[1-F(\widetilde{\phi})] \gamma .
\end{aligned}
$$

Accordingly, the derivatives of welfare with respect to $t$ and $\underline{\omega}$ are

$$
\begin{aligned}
\frac{\partial W}{\partial \underline{\omega}} & =[F(\Phi)-F(\widetilde{\phi})]+[-\underline{\omega}+\omega(\widetilde{\phi}, 0)+v(\widetilde{\varepsilon})+\gamma] f(\widetilde{\phi}(\underline{\omega}, t)) \widetilde{\phi}_{\underline{\omega}}(\underline{\omega}, t) \\
& -\int_{\widetilde{\phi}(\underline{\omega}, t)}^{\phi^{H}} \frac{v^{\prime}\left(\varepsilon^{i}\right)}{\omega_{e}\left(\phi^{i}, \varepsilon^{i}\right)} d F\left(\phi^{i}\right)
\end{aligned}
$$

and

$$
\frac{\partial W}{\partial t}=[-\underline{\omega}+\omega(\widetilde{\phi}, 0)+v(\widetilde{\varepsilon})+\gamma] f(\widetilde{\phi}(\underline{\omega}, t)) \widetilde{\phi}_{t}(\underline{\omega}, t) .
$$

At an interior optimum it must be that

$$
\frac{\partial W}{\partial t}=0 \rightarrow-\underline{\omega}+v(\widetilde{\varepsilon})+\omega(\widetilde{\phi}, 0)+\gamma=0
$$

which together with

$$
w^{d}-t-v(\widetilde{\varepsilon})-w^{u}=0
$$

imply

$$
t^{*}=\gamma+\left[w^{d}-w^{u}\right]-\left[\underline{\omega}^{*}-\omega\left(\widetilde{\phi}\left(\underline{\omega}^{*}, t^{*}\right), 0\right)\right] .
$$

Moreover, from $\frac{\partial W}{\partial t}=0$ we get

$$
\underline{\omega}-v(\widetilde{\varepsilon})-\omega(\widetilde{\phi}, 0)=\gamma
$$

thus

$$
\frac{\partial W}{\partial \underline{\omega}}=0 \rightarrow F(\Phi)-F\left(\widetilde{\phi}\left(\underline{\omega}^{*}, t\right)\right)=\int_{\widetilde{\phi}\left(\underline{\omega}^{*}, t^{*}\right)}^{\phi^{H}} \frac{v^{\prime}\left(\varepsilon\left(\phi^{i}, \underline{\omega}\right)\right)}{\omega_{e}\left(\phi^{i}, \varepsilon\left(\phi^{i}, \underline{\omega}\right)\right)} d F\left(\phi^{i}\right) .
$$




\section{A.5 Lemma 1}

Lemma 1 If tuition fees are not allowed then

$$
\frac{v^{\prime}(\tilde{\varepsilon})}{\omega_{e}(\tilde{\phi}, \tilde{\varepsilon})}>1 .
$$

Proof. Notice that a student exerting no effort can not be marginal (unless $\tilde{\phi}=\phi^{L}$ ) since her utility when achieving the degree, $\tilde{w}^{d}(\tilde{\phi}, \underline{\omega})$, is strictly greater than that if she does not attend school, $w^{u}(\tilde{\phi})$. Consequently, I only need to consider students who exert a strictly positive effort to achieve the degree.

The two following inequalities must hold with at least one of them being strict (both expressions will hold simultaneously with equality only in the case in which $\left.\phi^{H}=\phi^{L}\right)$.

$$
\tilde{w}^{d}(\tilde{\phi}, \underline{\omega}) \geq \omega(\tilde{\phi}, \tilde{\varepsilon})
$$

and

$$
\omega(\tilde{\phi}, 0) \geq \tilde{w}^{u}(\tilde{\phi}) .
$$

The first of these inequalities implies that

$$
\tilde{w}^{d}(\tilde{\phi}, \underline{\omega})-v(\tilde{\varepsilon}) \geq \omega(\tilde{\phi}, \tilde{\varepsilon})-v(\tilde{\varepsilon})
$$

and the second that

$$
\omega(\tilde{\phi}, 0) \geq \tilde{w}^{u}(\tilde{\phi})
$$

Now let $\tilde{e}^{*}$ satisfy

$$
\frac{v^{\prime}\left(\tilde{e}^{*}\right)}{\omega_{e}\left(\tilde{\phi}, \tilde{e}^{*}\right)}=1
$$

Note that $\tilde{e}^{*}$ is the effort level that and individual with ability $\tilde{\phi}$ would exert in a frictionless labor market. Suppose that the marginal student needs to exert an effort level $\tilde{\varepsilon} \leq \tilde{e}^{*}$ to achieve the standard. Since $\omega\left(\phi^{i}, e^{i}\right)-v\left(e^{i}\right)$ is concave and $\tilde{\varepsilon}>0, \tilde{\varepsilon} \leq \tilde{e}^{*}$ implies that

$$
\omega(\tilde{\phi}, \tilde{\varepsilon})-v(\tilde{\varepsilon})>\omega(\tilde{\phi}, 0) .
$$

Equations (14), (15) and (17) imply that (recall that either 14 or 15 must be satisfied with strict inequality)

$$
\tilde{w}^{d}(\tilde{\phi}, q, \underline{\omega})-v(\tilde{\varepsilon})>\tilde{w}^{u}(\tilde{\phi}) .
$$


Which contradicts the fact that

$$
\tilde{w}^{d}(\tilde{\phi}, \underline{\omega})-v(\tilde{\varepsilon})=\tilde{w}^{u}(\tilde{\phi}, \underline{\omega}) .
$$

Consequently equation (16) cannot hold.

Moreover, this also implies that the marginal student must exert an effort level $\tilde{\varepsilon}>\tilde{e}^{*}$. Thus,

$$
\frac{v^{\prime}(\tilde{\varepsilon})}{\omega_{e}(\tilde{\phi}, \tilde{\varepsilon}, q)}>1
$$

from the concavity of $\omega\left(\phi^{i}, e^{i}, q\right)-v\left(e^{i}\right)$.

\section{A.6 The optimal individual grading standard}

The grading standard that maximizes the willingness to pay for attending school by the marginal individual results from maximizing $\Delta\left(\phi^{i}, \underline{\omega}\right)$ with respect to $\underline{\omega}$. The FOC $\left(\Delta_{\underline{\omega}}\left(\phi^{i}, \underline{\omega}^{i}\right)=0\right)$ and $\operatorname{SOC}\left(\Delta_{\underline{\omega \omega}}\left(\phi^{i}, \underline{\omega}^{i}\right) \leq 0\right)$ of this problem are, respectively,

$$
\frac{F(\Phi)-F\left(\phi^{i}\right)}{1-F\left(\phi^{i}\right)}-\frac{v^{\prime}\left(\varepsilon^{i}\right)}{\omega_{e}\left(\phi^{i}, \varepsilon^{i}\right)}=0
$$

and

$$
\frac{f(\Phi)}{1-F\left(\phi^{i}\right)} \frac{1}{\omega_{\phi}(\Phi, 0)}-\left[\frac{v^{\prime \prime}\left(\varepsilon^{i}\right)}{\left[\omega_{e}\left(\phi^{i}, \varepsilon^{i}\right)\right]^{2}}-\frac{v^{\prime}\left(\varepsilon^{i}\right) \omega_{e e}\left(\phi^{i}, \varepsilon^{i}\right)}{\left[\omega_{e}\left(\phi^{i}, \varepsilon^{i}\right)\right]^{3}}\right] \leq 0
$$

where $\underline{\omega}^{i}$ denotes the optimal grading standard for an individual with ability $\phi^{i}$ when she is the marginal individual. Assume that (19) is satisfied, then the comparative static of $\underline{\omega}^{i}$ with respect to $\phi^{i}$ follows from differentiation of (18) and is given by

$$
\frac{\partial \underline{\omega}^{i}}{\partial \phi^{i}}=-\frac{\Delta_{\underline{\omega}} \phi^{i}\left(\phi^{i}, \underline{\omega}^{i}\right)}{\Delta_{\underline{\omega \omega}}\left(\phi^{i}, \underline{\omega}^{i}\right)}
$$

Then, $\partial \underline{\omega}^{i} / \partial \phi^{i} \geq 0$ if $\Delta_{\underline{\omega} \phi^{i}}\left(\phi^{i}, \underline{\omega}^{i}\right) \geq 0$. Sufficient conditions for $\Delta_{\underline{\omega} \phi^{i}}\left(\phi^{i}, \underline{\omega}^{i}\right) \geq$ 0 are that the hazard rate is increasing, $\omega$ concave in both arguments and $\omega_{\phi e}>0$.

The previous argument follows from inspection of $\Delta_{\underline{\omega} \phi^{i}}\left(\phi^{i}, \underline{\omega}^{i}\right) \geq 0$ which is given by

$$
\begin{aligned}
\Delta_{\underline{\omega} \phi^{i}}\left(\phi^{i}, \underline{\omega}^{i}\right)= & -\frac{f\left(\phi^{i}\right)}{1-F\left(\phi^{i}\right)} \frac{1-F(\Phi)}{1-F\left(\phi^{i}\right)}+\frac{v^{\prime}\left(\varepsilon^{i}\right)}{\left[\omega_{e}\left(\phi^{i}, \varepsilon^{i}\right)\right]^{2}} \omega_{\phi e}\left(\phi^{i}, \varepsilon^{i}\right) \\
& +\left[\frac{v^{\prime \prime}\left(\varepsilon^{i}\right)}{\left[\omega_{e}\left(\phi^{i}, \varepsilon^{i}\right)\right]^{2}}-\frac{v^{\prime}\left(\varepsilon^{i}\right) \omega_{e e}\left(\phi^{i}, \varepsilon^{i}\right)}{\left[\omega_{e}\left(\phi^{i}, \varepsilon^{i}\right)\right]^{3}}\right] \omega_{\phi}\left(\phi^{i}, \varepsilon^{i}\right) .
\end{aligned}
$$


Note that $\Delta_{\underline{\omega} \phi}\left(\phi^{i}, \underline{\omega}\right)>0$ if (recall we have assumed $\omega_{\phi e} \geq 0$ )

$$
\frac{f\left(\phi^{i}\right)}{1-F\left(\phi^{i}\right)} \frac{1-F(\Phi)}{1-F\left(\phi^{i}\right)} \frac{1}{\omega_{\phi}\left(\phi^{i}, \varepsilon^{i}\right)} \leq\left[\frac{v^{\prime \prime}\left(\varepsilon^{i}\right)}{\left[\omega_{e}\left(\phi^{i}, \varepsilon^{i}\right)\right]^{2}}-\frac{v^{\prime}\left(\varepsilon^{i}\right) \omega_{e e}\left(\phi^{i}, \varepsilon^{i}\right)}{\left[\omega_{e}\left(\phi^{i}, \varepsilon^{i}\right)\right]^{3}}\right] .
$$

The SOC implies that

$$
\frac{f(\Phi)}{1-F\left(\phi^{i}\right)} \frac{1}{\omega_{\phi}(\Phi, 0)} \leq\left[\frac{v^{\prime \prime}\left(\varepsilon^{i}\right)}{\left[\omega_{e}\left(\phi^{i}, \varepsilon^{i}\right)\right]^{2}}-\frac{v^{\prime}\left(\varepsilon^{i}\right) \omega_{e e}\left(\phi^{i}, \varepsilon^{i}\right)}{\left[\omega_{e}\left(\phi^{i}, \varepsilon^{i}\right)\right]^{3}}\right] .
$$

Since the right hand sides of equations (20) and (21) are the same, if (21) is satisfied, then $\Delta_{\omega \phi} \geq 0$ if

$$
\frac{f\left(\phi^{i}\right)}{1-F\left(\phi^{i}\right)} \frac{1}{\omega_{\phi}\left(\phi^{i}, \varepsilon^{i}\right)} \leq \frac{f(\Phi)}{1-F(\Phi)} \frac{1}{\omega_{\phi}(\Phi, 0)} .
$$

Recalling the definition of $\varepsilon^{i}(22)$ holds if

$$
\frac{\partial}{\partial \phi}\left[\frac{f(\phi)}{1-F(\phi)} \frac{1}{\omega_{\phi}(\phi, \varepsilon)}\right] \geq 0
$$

which is satisfied if the hazard rate is increasing, $\omega_{\phi e}>0$ and $\omega_{\phi \phi} \leq 0$. 


\section{References}

Betts, J. R., "The impact of educational standards on the level and distribution of earnings," American Economic Review 88 (1998), 266-275.

Betts, J. R. and J. Grogger, "The impact of grading standards on student achievement, educational attainment, and entry-level earnings," Economics of Education Review 22 (2003), 343-352.

Brunello, G. and L. Rocco, "Educational Standards in private and public schools," The Economic Journal 118 (2008), 1866-1887.

Costrell, R. M., "A simple model of educational standards," American Economic Review 84 (1994), 956-971.

De Fraja, G. and P. Landeras, "Could Do Better: The Effectiveness of Incentives and Competition in Schools," Journal of Public Economics 90 (2006), 189-213.

Epple, D. and R. E. Romano, "Competition between private and public schools, vouchers and peer-group effects," The American Economic Review 88 (1998), 31-62.

Epple, D., R. E. Romano and H. Siege, "Peer effects, financial aid and selection of students into colleges and universities: an empirical analysis," Journal of Applied Econometrics 13 (2003), 501-525.

Figlio, D. N. and M. E. Lucas, "Do high grading standard affect student performance?," Journal of Public Economics 88 (2004), 1815-1834.

Gary-Bobo, R. J. and A. Tranoy, "Efficient tuition fees and examinations and subsidies," Journal of the European Economic Association, 2005.

Hanushek, E. A., "Publicly provided education," in A. J. Auerbach and M. Feldstein, eds., Handbook of Public Economics IV (Amsterdam: North-Holland, 2002), 2046-2141.

Kroch, E. A. and K. Sjoblom, "Schooling as human capital or signaling," Journal of Human Resources 19 (1994), 156-180.

Lang, K. and D. Kropp, "Human capital versus sorting," American Economic Review 84 (1986), 353-358.

Lizzeri, A., "Information revelation and certification intermediaries," RAND Journal of Economics 30 (1999), 214-231. 
Nechyba, T., "Income and Peer Quality Sorting in Public and Private Schools," in E. Hanushek and F. Welch, eds., Handbook of the Economics of Education Public Economics (Amsterdam: North-Holland, 2006), 1327-1368.

Riley, J. G., "Testing the educational screening hypothesis," Journal of Political Economy 87 (1979), S227-S252.

Spence, M., "Monopoly, quality and regulation," The Bell Journal of Economics 6 (1975), 163-172.

Stinebrickner, R. and T. R. Stinebrickner, "The casual effect of studying on academic performance," The B. E. Journal of Economic Analysis 6 Policy (Frontiers) 8 (2008), Article 14.

Wolpin, K., "Education and screening," American Economic Review 67 (1977), 949-958. 